\title{
EMERGÊNCIA DE PLÂNTULAS ORIUNDAS DE SEMENTES RECÉM- COLHIDAS E ARMAZENADAS DE Copaifera langsdorffii Desf. (CAESALPINIOIDEAE), TRIÂNGULO MINEIRO, BRASIL ${ }^{1}$
}

\author{
Regina dos Santos Pereira ${ }^{2}$, Denise Garcia de Santana ${ }^{3}$ e Marli Aparecida Ranal ${ }^{4}$
}

\begin{abstract}
RESUMO - Copaifera langsdorffii é uma espécie em perigo de extinção, com dormência múltipla em suas sementes e baixa resistência ao armazenamento. Nesse sentido, é importante saber se as sementes perdem viabilidade a partir do ponto de maturidade fisiológica e se resistem à perda de água durante o armazenamento. Quatro experimentos foram instalados com sementes coletadas em julho (matriz 1) e agosto de 2005 (matriz 2), no Vale do Rio Araguari, MG, dois com sementes recém-colhidas e dois com sementes armazenadas em câmara fria. A perda de $31 \%$ de água das sementes coletadas no solo, em relação às colhidas de frutos aderidos à árvore, reduziu em aproximadamente $10 \%$ o porcentual de emergência. A presença do arilo nas sementes recém-colhidas causou aumento do coeficiente de variação de emergência, indicando que essa estrutura possui substâncias inibidoras de germinação. Com o armazenamento, as sementes perderam viabilidade, diminuindo significativamente os porcentuais de emergência, o que indica que as sementes dessa espécie possuem certo grau de recalcitrância, com baixa resistência à perda de água após a maturidade fisiológica. Para a obtenção de maior número de mudas, em menor tempo e com maior sincronia, recomenda-se a utilização de sementes oriundas de frutos recém-abertos, ainda aderidos à árvore, com semeadura sem arilo e com escarificação.
\end{abstract}

Palavras-chave: Armazenamento, copaíba e recalcitrância.

\section{SEEDLING EMERGENCE FROM NEWLY-COLLECTED AND STORAGE SEEDS OF Copaifera langsdorffii Desf. (CAESALPINOIDEAE), TRIÂNGULO MINEIRO, BRAZIL}

\begin{abstract}
Copaifera langsdorffii is a threatened species that presents seeds with multiple dormancy and low resistance to storage. Thus, it is interesting to know if the seeds lose viability from the physiological maturity point and if they resist to desiccation during the storage period. Four experiments were conducted using seeds from the Araguari River Valley, MG (matrix 1, July and matrix 2, August 2005). Two of them had newlycollected seeds and the other two used seeds stored in cold chamber. The loss of $31 \%$ of water from the seeds collected from the soil in relation to the seeds collected from the tree reduced the percentage of emergence in about $10 \%$. The presence of aril increased the value of the coefficient of variation of the emergence, indicating the presence of germination inhibitors in this part of the seeds. The seeds had lost viability after storage, reducing significantly the percentages of emergence. This characteristic indicates that seeds of this species have some degree of recalcitrance. To obtain a high number of seedlings in short time, with high synchrony, seeds collected from newly-opened fruits, directly of the tree, without aril, and scarified are recommended.
\end{abstract}

Keywords: Copaíba, recalcitrance and storage.

\footnotetext{
${ }^{1}$ Recebido em 15.10.2007 e aceito para publicação em 29.05.2009.

${ }^{2}$ Graduação em Ciências Biológicas pela Universidade Federal de Uberlândia (UFU). E-mail: <regina.s.pereira@hotmail.com>.

${ }^{3}$ Instituto de Ciências Agrarias da UFU. E-mail: <dgsantana@umuarama.ufu.br>.

${ }^{3}$ Instituto de Biologia da UFU. E-mail: <ranal@ufu.br>.
} 


\section{INTRODUÇÃO}

Copaifera langsdorffii Desf. é uma espécie arbórea da família Leguminosae (FABACEAE), subfamília Caesalpinioideae, denominada popularmente copaíba, óleo e pau-de-óleo. Essa espécie, de ampla distribuição no Brasil (FREITAS e OLIVEIRA, 2002), atinge mais de $20 \mathrm{~m}$ de altura (PEDRONI et al., 2002); as flores, em média 125 por inflorescência, paniculada e terminal, são polinizadas por Apis melifera e Trigona sp. (FREITAS e OLIVEIRA, 2002). O fruto é do tipo legume (BARROSO et al., 1999), deiscente, ovóide, castanhoclaro quando maduro, com uma semente; a semente é preta, oblonga; recoberta parcialmente por arilo alaranjado (CARVALHO, 2003), de consistência carnosa e mucilaginosa, composto por carboidratos (RODRIGUES et al., 2000) e lipídeos (LEAL e OLIVEIRA, 1998; PIZO et al., 2005). A frutificação é supra-anual, com anos de intensa produção, seguidos por anos de pouca ou nenhuma produção (NEWSTRON et al., 1994; PEDRONI et al., 2002), sendo essa tendência trienal (DIAS, 2005). Essa variação no ciclo reprodutivo causa flutuações no tamanho das populações, apesar de a espécie manter um banco de plantas jovens que garante a autorregeneração dessas populações (SCHIAVINI et al., 2001).

A árvore desperta grande interesse comercial por seu potencial ornamental (LORENZI, 1992), por sua madeira (CARVALHO, 2003) e pela produção de óleoresina (óleo de copaíba), que pode ser utilizado como biodiesel, como matéria-prima para a indústria de verniz e tintas ou como produto medicinal (VEIGA JÚNIOR e PINTO, 2002; CARVALHO, 2003; RIGAMONTEAZEVEDO et al., 2006). Além disso, extratos de cascas e folhas agem como aleloquímicos, sendo considerados promissores no controle de Bidens pilos $a$ L. (SANTANA et al., 2006). Por despertar interesses tão diversificados, Copaifera langsdorffii tem sofrido intensa exploração e está na lista das espécies que correm perigo de extinção no Estado de São Paulo (CARVALHO, 2003), embora não esteja incluída na lista oficial do IBAMA (IBAMA, 1992). No Pontal do Paranapanema, região mais recentemente desflorestada de São Paulo, a fragmentação ainda não causou perda de alelos na espécie, mas estão sendo sugeridos sistemas agroflorestais para favorecer o fluxo gênico entre fragmentos (MARTINS et al., 2008).

As sementes de Copaifera langsdorffii apresentam dormência tegumentar, superada por meio da escarificação (ALMEIDA, 1998). Há ainda registros sobre dormência ocasional, causada pela presença de cumarina no tegumento (EIRA e MARTINS NETTO, 1998), cuja concentração diminui à medida que as sementes amadurecem (MELO et al., 1998). Além disso, se a espécie apresenta inibidores de crescimento na casca, nas folhas (SANTANA et al., 2006), no tegumento da semente (EIRA e MARTINS NETTO, 1998), no eixo embrionário e nos cotilédones (POLO e PAES, 1994), é possível que essas substâncias também estejam presentes no arilo das sementes, como foi sugerido por Rodrigues et al. (2000).

Os dados referentes à tolerância ao armazenamento das sementes dessa espécie em câmara fria são contraditórios. Eira et al. (1992) consideraram as sementes da espécie como ortodoxas, com alta longevidade e capazes de manter a viabilidade por quatro anos. No entanto, Salomão et al. (2003) indicaram baixa longevidade das sementes, cerca de dois meses, sob condições similares de armazenamento. Tecnologias mais avançadas, como a eletroforese, tentaram explicar esse comportamento anômalo usando a técnica de envelhecimento artificial. Todavia, não foram detectadas modificações nos padrões eletroforéticos de proteínas solúveis entre sementes recém-colhidas e envelhecidas artificialmente por diferentes tempos (CARVALHO et al., 2006).

Em razão da abundância de óleo nos tecidos de reserva das sementes dessa espécie (CRESTANA e BELTRANI, 1988), pode ser que a baixa resistência das sementes ao armazenamento não seja decorrência da baixa resistência à perda de água e, sim, em virtude desse tipo de reserva. Segundo Marcos Filho (2005), a instabilidade química dos lipídeos constitui um dos fatores preponderantes para a queda do desempenho das sementes de várias espécies.

Este estudo teve por objetivos avaliar a emergência de plântulas oriundas de sementes recém-colhidas de Copaifera langsdorffii, analisando-se a influência do arilo e da escarificação nesse processo, associandose, ainda, essas informações ao teor de água das sementes recém-colhidas e armazenadas.

\section{MATERIAL E MÉTODOS}

\subsection{Locais de coleta}

Sementes de Copaifera langsdorffii foram coletadas a partir de duas matrizes, em julho (matriz 1) e em agosto de 2005 (matriz 2), no Vale do Rio Araguari, Minas Gerais. 
Foram marcadas, inicialmente, 10 matrizes para a coleta de sementes, mas a supra-anualidade na reprodução dessa espécie permitiu coletar frutos de apenas duas matrizes na safra de 2005. A matriz número 1 está localizada em mata ciliar ( $18^{\circ} 53^{\prime} 48^{\prime \prime}$ 'S e $48^{\circ} 02^{\prime} 25^{\prime}$ ' W) e a número 2 , em Floresta Estacional Semidecidual (1840’21" S e $48^{\circ} 25^{\prime} 35^{\prime}$ ' W). A região é de clima do tipo Aw, segundo a classificação de Köppen (1948), caracterizada por apresentar inverno seco de abril a setembro e verão chuvoso de outubro a março (RANAL, 2003).

\subsection{Teor de água}

O teor de água das sementes recém-colhidas das duas matrizes foi determinado logo após a coleta e beneficiamento, com secagem a 70 e $105^{\circ} \mathrm{C}$ até massa constante e com base na massa da matéria seca. Nas sementes armazenadas, foi determinado o teor de água apenas naquelas oriundas da matriz 2; armazenadas por quatro meses, a $70{ }^{\circ} \mathrm{C}$ e por oito meses, a $105^{\circ} \mathrm{C}$. Em cada temperatura foram avaliadas oito amostras, cada uma delas com 11 sementes desprovidas de arilo, com massa média de 5,2 g. A comparação entre as médias foi feita pelo teste $t$ de Student com relação a dados com normalidade ou de Mann-Whitney no tocante a dados sem normalidade.

\subsection{Emergência de plântulas oriundas de sementes recém-colhidas e armazenadas}

Da matriz 1 foram coletadas sementes do solo, recém-liberadas, e de frutos fechados verdolengos aderidos à árvore, contendo sementes que haviam atingido a maturidade fisiológica, indicada pela deiscência espontânea de parte dos frutos e pela coloração semelhante à dos frutos abertos aderidos à árvore. Os frutos coletados foram secos ao ar por dois dias, em local sombreado, até a deiscência natural. Para a matriz 2, foram coletados frutos abertos, ainda aderidos à árvore, contendo sementes com algum grau de ressecamento, indicado pela coloração mais forte do arilo e pelo início do seu ressecamento.

Após a secagem, as sementes foram beneficiadas manualmente para a separação do fruto e retirada do arilo, quando foi o caso. Posteriormente, foram instalados os experimentos de emergência e as sementes restantes, sem arilo, armazenadas em câmara fria a $18^{\circ} \mathrm{Ce} 12 \%$ UR do ar.

O experimento para avaliar a emergência de plântulas oriundas de sementes recém-colhidas da matriz 1 foi instalado em delineamento inteiramente casualizado
(DIC), com (1) sementes coletadas de frutos aderidos à árvore, com arilo e intactas; (2) sementes coletadas de frutos aderidos à árvore, sem arilo e intactas; (3) sementes coletadas no solo, sem arilo e intactas; (4) sementes coletadas no solo, sem arilo e escarificadas com esmeril em uma das laterais, ao longo do comprimento, antes de atingir o embrião (abertura com cerca de 3 mm de diâmetro), totalizando quatro tratamentos com cinco repetições de 30 sementes cada. Em razão do número restrito de sementes, na matriz 2 sementes sem arilo, escarificadas e intactas, foram utilizadas, avaliando-se, em cada tratamento, uma amostra com 100 sementes.

A primeira retirada de sementes da câmara fria foi realizada quatro meses após a data de armazenamento. Com elas, foi instalado um terceiro experimento de emergência, utilizando-se sementes das duas matrizes, intactas e escarificadas, sem arilo. A segunda retirada aconteceu com oito meses de armazenamento, quando foi montado o quarto experimento de emergência, empregando-se sementes intactas das duas matrizes. Esses dois últimos experimentos também foram avaliados com base em uma amostra de 100 sementes em cada tratamento.

A semeadura foi feita a $1 \mathrm{~cm}$ de profundidade, em bandejas de poliestireno expandido, preenchidas com vermiculita e substrato comercial (1:1). Os experimentos foram mantidos em estufa com redução de $50 \%$ de luz e irrigados diariamente. As avaliações foram realizadas a cada $24 \mathrm{~h}$, tendo como critério de contagem o aparecimento de qualquer parte da plântula acima do substrato.

As pressuposições do modelo do delineamento experimental (normalidade e homogeneidade) foram testadas segundo Santana e Ranal (2004). As medidas de emergência e testes estatísticos foram realizados de acordo com Santana e Ranal (2004), Carvalho et al. (2005) e Ranal e Santana (2006). Nos experimentos de emergência baseados em amostras independentes, o porcentual de emergência, o tempo médio, a velocidade média e a incerteza do processo foram comparados pelo teste $t$ de Student (CARVALHO et al., 2005). A expressão do teste $t$ de Student e os graus de liberdade adotados foram os recomendados para comparações entre amostras com variâncias, apesar de desconhecidas, consideradas heterogêneas (SANTANA e RANAL, 2004). As comparações referentes ao armazenamento foram realizadas graficamente, utilizando-se intervalos de confiança com 0,05 de significância associados ao valor calculado.

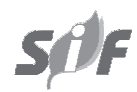

R. Árvore, Viçosa-MG, v.33, n.4, p.643-652, 2009 


\section{RESULTADOS E DISCUSSÃO}

\subsection{Teor de água das sementes}

O teor de água das sementes recém-colhidas de Copaifera langsdorffii, obtido a $105{ }^{\circ} \mathrm{C}$, foi significativamente maior do que o determinado a $70^{\circ} \mathrm{C}$, sendo registrados $48,94 \%$ a $70^{\circ} \mathrm{C}$ e $58,43 \%$ a $105^{\circ} \mathrm{C}$ nas sementes da matriz 1 , coletadas de frutos aderidos à árvore $(t=2,656 ; P=0,0188)$. Nas sementes da mesma matriz, coletadas no solo, o teor de água foi de $18,21 \%$ a $70{ }^{\circ} \mathrm{C}$ e de $20,91 \%$ a $105^{\circ} \mathrm{C}(t=3,548 ; P=0,0032)$ e nas sementes da matriz 2 , de $10,40 \%$ a $70{ }^{\circ} \mathrm{C}$ e de $14,65 \%$ a $105{ }^{\circ} \mathrm{C}(t=11,586 ; P=0,0001)$. Os resultados também mostraram que há perda de água pelas sementes após a abertura do fruto, mesmo aderido à árvore, como foi o caso das coletadas a partir da matriz 2 .

As sementes da matriz 2, armazenadas por quatro meses, apresentaram teor de água de $8,36 \%$ a $70^{\circ} \mathrm{C}$, valor esse significativamente menor do que o das sementes recém-colhidas, avaliado na mesma temperatura $(t=7,477$; $P=0,0001)$. As sementes dessa mesma matriz, armazenadas por oito meses, apresentaram $19,20 \%$ de água a $105^{\circ} \mathrm{C}$, teor significativamente maior do que o das sementes recém-colhidas, avaliado na mesma temperatura ( $U=64 ; P=0,0002)$. Esse acréscimo no teor de água de sementes armazenadas por oito meses foi decorrente da elevação da umidade relativa do ar na câmara fria.
Essa variação no teor de água registrada depende do grau de maturidade das sementes, da umidade relativa do ar durante o período de dispersão e da forma como as sementes são manipuladas (beneficiamento). É importante ressaltar ainda que espécies que liberam sementes na época seca estão sujeitas à desidratação e reidratação, dependendo da umidade do ar circundante, especialmente para aquelas que são anemocóricas ou zoocóricas com frutos secos, como é o caso de Copaifera langsdorffii.

\subsection{Emergência de plântulas oriundas de sementes recém-colhidas e armazenadas}

No experimento realizado com sementes recémcolhidas da matriz 1 , os maiores porcentuais de emergência de plântulas e a menor variabilidade $\left(C V_{\mathrm{E}}\right)$ foram registrados nos tratamentos cujas sementes foram coletadas de frutos aderidos à árvore, em relação às colhidas no solo (Tabela 1). Essa resposta pode ter sido consequência do menor teor de água das sementes coletadas no solo e da perda de água desigual entre as sementes, causando diferença no seu estado fisiológico. Para essa espécie, é então recomendável a coleta de sementes diretamente da árvore, tomandose como ponto de referência a queda espontânea de sementes no solo, o que confirma os relatos feitos por Borges e Borges (1979). Nesse ponto, as sementes apresentam ótima germinação (SALOMÃO et al., 2003), por estarem com maturidade fisiológica plena.

Tabela 1 - Emergência de plântulas oriundas de sementes recém-colhidas da matriz 1 de Copaifera langsdorffii Desf., Vale do Rio Araguari, MG, safra 2005, mantidas em estufa semiaberta

Table 1 - Seedling emergence of Copaifera langsdorffii Desf. from newly-collected seeds of matrix number 1, Araguari River Valley, MG, 2005 crop, cultivated in green house

\begin{tabular}{|c|c|c|c|c|c|c|c|}
\hline \multirow{2}{*}{$\begin{array}{c}\text { Medida } \\
\text { (unidade) }\end{array}$} & \multicolumn{2}{|c|}{ Sementes da árvore, intactas } & \multicolumn{2}{|c|}{ Sementes do solo, sem arilo } & \multirow[b]{2}{*}{$W$} & \multirow[b]{2}{*}{${ }^{1} F$} & \multirow[b]{2}{*}{${ }^{2} \mathrm{~F} / \mathrm{H}$} \\
\hline & com arilo & sem arilo & intactas & escarificadas & & & \\
\hline $\begin{array}{c}E(\%) \\
C V_{\mathrm{E}}(\%)\end{array}$ & $\begin{array}{c}89,33 \pm 7,61 \mathrm{a} \\
8,52\end{array}$ & $\begin{array}{c}96,00 \pm 1,49 \mathrm{a} \\
1,55\end{array}$ & $\begin{array}{c}66,67 \pm 9,72 b \\
14,58\end{array}$ & $\begin{array}{c}76,00 \pm 7,60 \mathrm{~b} \\
10,00\end{array}$ & 0,947 & 1,686 & 16,363 \\
\hline $\bar{t}(\mathrm{dia})$ & $37,57 \pm 2,45 a$ & $37,48 \pm 2,24 a$ & $41,02 \pm 1,44 a$ & $37,45 \pm 2,60 \mathrm{a}$ & 0,961 & $\mathbf{0 , 7 7 6}$ & 3,132 \\
\hline $\bar{v}\left(\operatorname{dia}^{-1}\right)$ & $0,0267 \pm 0,0016 \mathrm{a}$ & $0,0268 \pm 0,0016 a$ & $0,0244 \pm 0,0009 a$ & $0,0268 \pm 0,0019 \mathrm{a}$ & 0,956 & 1,115 & 2,855 \\
\hline$C V_{\mathrm{t}}(\%)$ & $13,81 \pm 0,99 a$ & $12,70 \pm 3,82 \mathrm{a}$ & $23,86 \pm 9,23 a$ & $13,80 \pm 4,78 \mathrm{a}$ & $\mathbf{0 , 9 2 1}$ & 7,732 & 8,486 \\
\hline$V E$ (plântula $\operatorname{dia}^{-1}$ ) & $0,7287 \pm 0,0888 \mathrm{ab}$ & $0,7818 \pm 0,0503 a$ & $0,5065 \pm 0,0607 \mathrm{c}$ & $0,6243 \pm 0,0887 \mathrm{bc}$ & $\mathbf{0 , 9 5 0}$ & 0,643 & 13,468 \\
\hline$I$ (bit) & $3,1067 \pm 0,2491 \mathrm{a}$ & $3,1199 \pm 0,1118 \mathrm{a}$ & $3,1357 \pm 0,2623 a$ & $3,1210 \pm 0,2003 \mathrm{a}$ & 0,969 & 1,411 & 0,015 \\
\hline$Z$ & $0,1035 \pm 0,0223 a$ & $0,1053 \pm 0,0118 \mathrm{a}$ & $0,0913 \pm 0,0254 a$ & $0,0910 \pm 0,0210 \mathrm{a}$ & $\mathbf{0 , 9 5 0}$ & 1,696 & 0,681 \\
\hline
\end{tabular}

$E$ : porcentual de emergência; $C V_{\mathrm{E}}$ : coeficiente de variação da porcentagem de emergência; $\bar{t}$ : tempo médio de emergência; $C V$ : coeficiente de variação do tempo; $\bar{v}$ : velocidade média de emergência; $I$ : incerteza; $Z$ : índice de sincronia de emergência; $W$ : estatística do teste de Shapiro-Wilk; valores em negrito indicam resíduos da ANOVA com distribuição normal $(P>0,05) ;{ }^{1} F$ : estatística do teste de Levene; valores em negrito indicam homogeneidade entre as variâncias $(P>0,05) ;{ }^{2} F / H$ : estatísticas dos testes de Snedecor e Kruskal-Wallis, respectivamente; valores em negrito indicam diferenças significativas entre tratamentos. Médias seguidas por letras iguais na linha não diferem significativamente, pelos testes de Tukey ou Dunn $(P>0,05)$.

R. Árvore, Viçosa-MG, v.33, n.4, p.643-652, 2009 
Além da perda de água das sementes coletadas no solo, nessas condições a suscetibilidade para a ação de fungos aumenta, reduzindo ainda mais a qualidade fisiológica e a viabilidade. Provavelmente, essas foram as causas da maior variabilidade na porcentagem de emergência de plântulas entre os tratamentos desse experimento.

Os porcentuais de emergência de plântulas não diferiram significativamente em sementes com arilo e sem arilo, mas a menor variabilidade na ausência de arilo (menor $C V_{\mathrm{E}}$ ) pode ter sido consequência da ausência do efeito dos inibidores presentes nessa estrutura (Tabela 1). O que reforça essa ideia é o aumento em até $50 \%$ da germinação de sementes dessa espécie sem arilo, registrado por Vilela (1993). Como a emergência de plântulas é lenta, as sementes ficaram, por muito tempo, sujeitas à ação de formigas, de fungos e bactérias presentes no substrato, que podem ter consumido o arilo antes que este pudesse exercer maior ação na emergência. Segundo Leal e Oliveira (1998) e Pizo et al. (2005), o arilo lipídico das sementes de Copaifera langsdorffii é removido por formigas, o que reduz a infestação de fungos e incrementa significativamente o sucesso de germinação das sementes dessa espécie. A presença do arilo facilita a dispersão secundária das sementes por formigas (LEAL e OLIVEIRA, 1998), podendo aumentar a chance de sua deposição em local adequado para a germinação. A presença dessa estrutura também pode estar envolvida na manutenção da dormência que ajusta a germinação ao início das chuvas.

A escarificação das sementes recém-colhidas da matriz 1 reduziu a variabilidade no processo de emergência (menor valor de $C V_{E}$ ), o que indica que o tegumento da semente pode restringir a emergência, apontando a dormência tegumentar da semente, conforme registrado por Almeida et al. (1998). Como a dispersão das sementes ocorre no final da estação seca e a perda de água acaba sendo inevitável, há endurecimento do tegumento. Também não pode ser esquecido que a escarificação representa uma abertura para a comunicação entre a semente e o meio, o que permite a lavagem do inibidor presente no tegumento e no embrião, devido às irrigações diárias.

A emergência das plântulas, independentemente das condições de coleta e da presença ou não do arilo, foi lenta e assíncrona; porém, com coeficientes de variação do tempo relativamente baixos, mostrando a baixa dispersão relativa do processo de emergência em relação ao tempo.

A lentidão na emergência de plântulas dessa espécie também foi relatada por Lorenzi (1992), que registrou a ocorrência do processo entre 20 e 40 dias.
Os coeficientes de variação do tempo para as plântulas oriundas de sementes de Copaifera langsdorffii da matriz 1 foram relativamente baixos, quando comparados com os valores obtidos nas outras espécies nativas, que estão entre 17 e 34\% (CARVALHO et al., 2005; DORNELES et al., 2005), o que mostra a menor dispersão da emergência de plântulas dessa espécie em relação ao tempo. Esse resultado é confirmado pelos polígonos de frequência relativa de emergência (Figura 1) que assinalam poucos picos com alta frequência, à semelhança do que foi registrado em núculas de Anacardium humile (CARVALHO et al., 2005), apesar da existência de picos isolados que fizeram o valor da incerteza ser elevado, caracterizando o processo como assíncrono.

O limite teórico máximo das medidas do processo de emergência de plântulas, tomando-se como ponto de referência o tamanho da amostra utilizada para estudo e o tamanho da amostra de plântulas emergidas (RANAL e SANTANA, 2006) mostra que a incerteza máxima teórica com relação às sementes de Copaifera langsdorffii, nas condições experimentais descritas, está entre 6,6 e 7,2 bits. Como os valores reais obtidos estão entre 3,1 e 4,2 bits, o grau de assincronia no processo de emergência das plântulas dessa espécie pode ser considerado intermediário. Do ponto de vista prático, essa característica facilita a formação de mudas, uma vez que, quanto menos assíncrono o processo de germinação ou emergência, maior o estande formado no mesmo intervalo de tempo, com mudas de idade e morfologia similares, o que facilita o manejo e a comercialização. A existência de picos mais concentrados no tempo significa tendência à menor assincronia, uma vez que a frequência de sobreposições de emergência no tempo é quantificada apenas pelo índice de sincronia $Z$. Como os limites desse índice são $0<\mathrm{Z} \leq 1$ e o maior valor registrado em sementes da matriz 1 foi de 0,1053 , a assincronia do processo é muito grande. Isso significa que qualquer procedimento que dependa de mudas dessa espécie precisará ser planejado contando com essa heterogeneidade etária.

Diferença significativa entre tratamentos no experimento realizado com sementes recém-colhidas da matriz 1 (Tabela 1) foi detectada apenas na porcentagem e velocidade de emergência de Maguire ( $V E)$. Esse resultado não é incomum, uma vez que a porcentagem de emergência interfere nos valores do $V E$, e essa medida mista de velocidade só tem valor comparativo se as porcentagens de emergência forem iguais. Essa 
característica do $V E$ foi detectada por Goodchild e Walker (1971) e Brown e Mayer (1988), tendo sido demonstrada numericamente por Santana e Ranal (2004) e Dorneles et al. (2005); por Santana et al. (2006), usando os valores de correlação entre medidas de germinação; e por Ranal e Santana (2006), com a abordagem teórica das medidas mistas de germinação onde está inserido o $V E$.

No experimento realizado com sementes oriundas da matriz 2, não foram registradas diferenças significativas entre os porcentuais de emergência de plântulas a partir de sementes intactas e escarificadas (Tabela 2). Entretanto, as sementes escarificadas

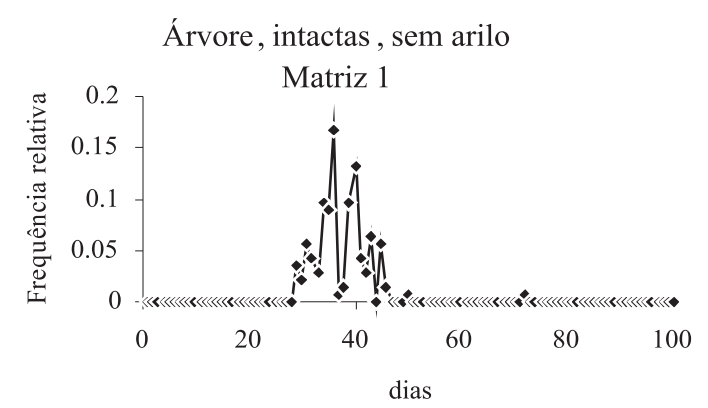

Solo, intactas, sem arilo

Matriz 1

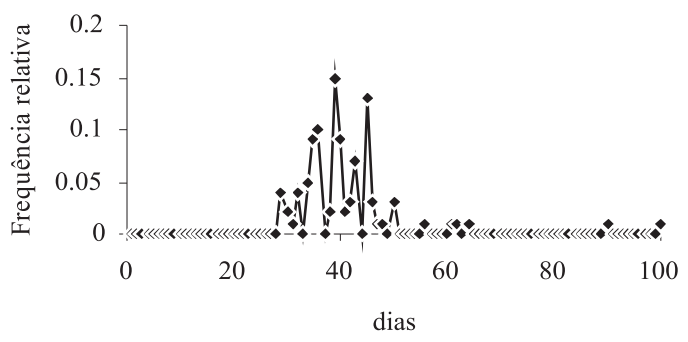

Árvore, Intactas, sem arilo

Matriz 2

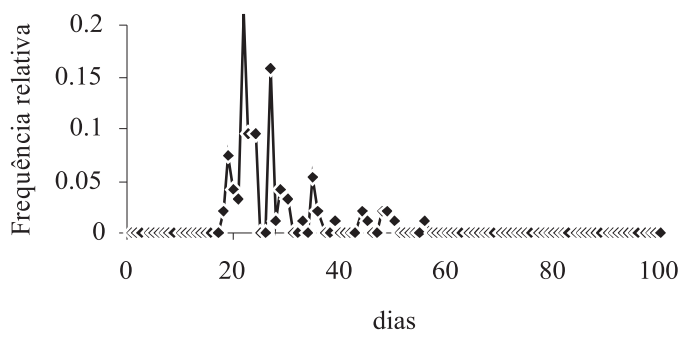

apresentaram menor tempo médio de emergência, maior velocidade, tiveram menor dispersão em relação ao tempo e foram mais sincrônicas quando comparadas com as sementes intactas. Apesar de as sementes terem sido coletadas com baixo teor de água, a porcentagem de emergência foi superior a $90 \%$, como o registro feito nas sementes da matriz 1 , coletadas no ponto de maturidade fisiológica e sem arilo. A emergência de plântulas oriundas de sementes intactas da matriz 2 foi mais heterogênea em relação ao tempo; porém, mais rápida, quando comparada com os resultados obtidos nas sementes da matriz 1 (Tabelas 1 e 2). Na incerteza e sincronia, as discrepâncias entre as matrizes foram menores.
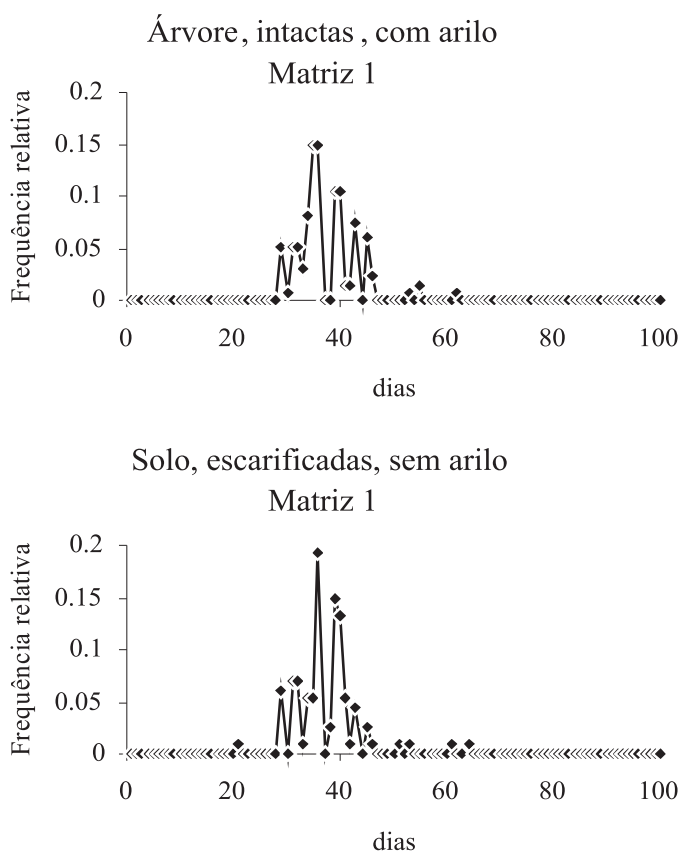

Árvore, Escarificadas, sem arilo Matriz 2

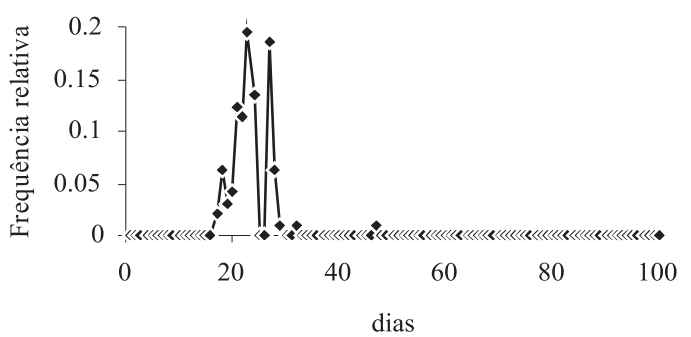

Figura 1 - Frequência relativa de emergência de plântulas de Copaifera langsdorffii Desf., Vale do Rio Araguari, MG, safra 2005, mantidas em estufa semiaberta.

Figure 1 - Relative frequency of seedling emergence of Copaifera langsdorffii Desf., Araguari River Valley, MG, 2005 crop, cultivated in green house.

R. Árvore, Viçosa-MG, v.33, n.4, p.643-652, 2009 
Tabela 2 -Emergência de plântulas oriundas de sementes recémcolhidas da matriz 2 de Copaifera langsdorffii Desf., Vale do RioAraguari, MG safra 2005, mantidas em estufa semiaberta

Table 2 - Seedling emergence of Copaifera langsdorffii Desf. from newly-collected seeds of matrix number 2, Araguari River Valley, MG, 2005 crop, cultivated in green house

\begin{tabular}{|c|c|c|}
\hline Medida (unidade) & S. I. & S. E. \\
\hline$E(\%)$ & 95,0 a & 97,0 a \\
\hline $\bar{t}(\mathrm{dia})$ & $27,01 \mathrm{~b}$ & $23,55 \mathrm{a}$ \\
\hline $\bar{v}\left(\mathrm{dia}^{-1}\right)$ & $0,0370 \mathrm{~b}$ & $0,0425 \mathrm{a}$ \\
\hline$C V_{\mathrm{t}}(\%)$ & 30,71 & 16,68 \\
\hline$V E$ (plântula $\left.\operatorname{dia}^{-1}\right)$ & 3,77 & 4,22 \\
\hline$I$ (bit) & $3,74 \mathrm{~b}$ & 3,19 a \\
\hline$Z$ & 0,0943 & 0,1209 \\
\hline
\end{tabular}

S.I.: sementes intactas; S.E.: sementes escarificadas; $E$ : porcentual de emergência; $\bar{t}$ : tempo médio de emergência; $\bar{v}$ : velocidade média de emergência; $C V_{\mathrm{t}}$ : coeficiente de variação do tempo; $I$ : incerteza; e $Z$ : índice de sincronia de emergência. Médias seguidas por letras iguais na linha não diferem significativamente, pelo teste $t$ de Student $(P>0,05)$.

Após a manutenção em câmara fria, a porcentagem de emergência de plântulas oriundas de sementes da matriz 1 foi reduzida significativamente aos quatro e oito meses de armazenamento, em relação às recém-
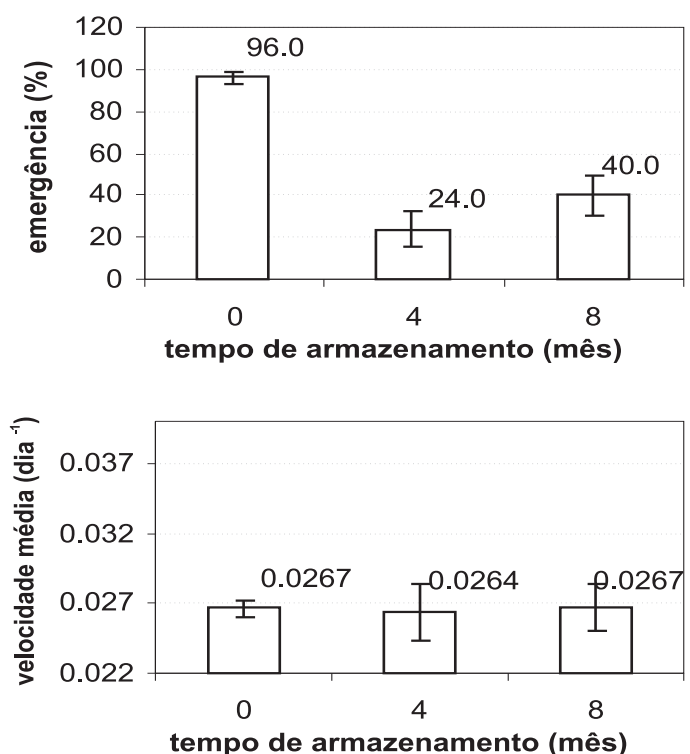

colhidas (Figura 2). A emergência foi lenta e assíncrona, independentemente da idade das sementes, com aumento significativo da assincronia ao final de oito meses (Figura 2). As sementes da matriz 2 tiveram comportamento similar às da matriz 1 , no que se refere ao declínio significativo da porcentagem de emergência com o tempo de armazenamento, porém com aumento significativo dessa porcentagem aos oito meses, em relação aos quatro meses (Figura 3). Como as sementes recém-colhidas dessa matriz estavam com menor teor de água do que as da matriz 1, os danos durante o armazenamento parecem ter sido menores, permitindo que, ao final de oito meses, $52 \%$ das sementes pudessem produzir plântulas. Some-se a isso que o aumento da umidade relativa do ar da câmara fria, ocorrido entre quatro e oito meses, deve ter facilitado reparos celulares, com manutenção da viabilidade de maior número de sementes. De qualquer forma, as sementes armazenadas das duas matrizes perderam consideravelmente viabilidade, mostrando baixa resistência ao armazenamento, o que confirma a baixa longevidade descrita por Salomão et al. (2003), podendo-se suspeitar da existência de algum grau de recalcitrância nessas sementes.
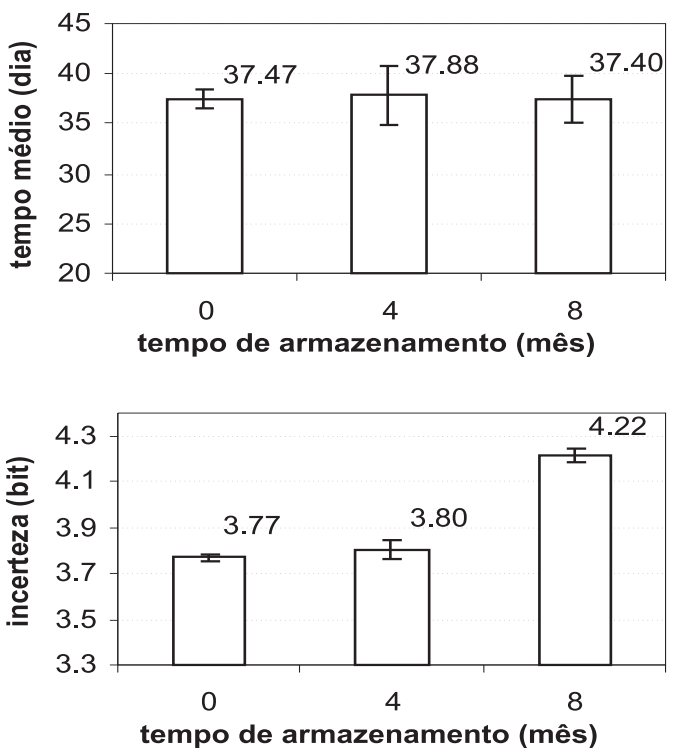

Figura 2 - Emergência de plântulas oriundas de sementes da matriz 1 recém-colhidas (sem arilo e intactas) e de sementes armazenadas por quatro e oito meses (sem arilo e intactas) de Copaifera langsdorffii Desf., Vale do Rio Araguari, MG, safra 2005, mantidas em estufa semiaberta. As barras representam o intervalo de confiança a 0,05 de significância.

Figure 2 -Seedling emergence from newly-collected seeds of the matrix 1, (without aril and without scarification) and stored during four and eight months (without aril and without scarification) of Copaifera langsdorffii Desf.; Araguari River Valley, MG, 2005 crop, cultivated in green house. The bars represent the confidence interval at 0.05 of significance. 

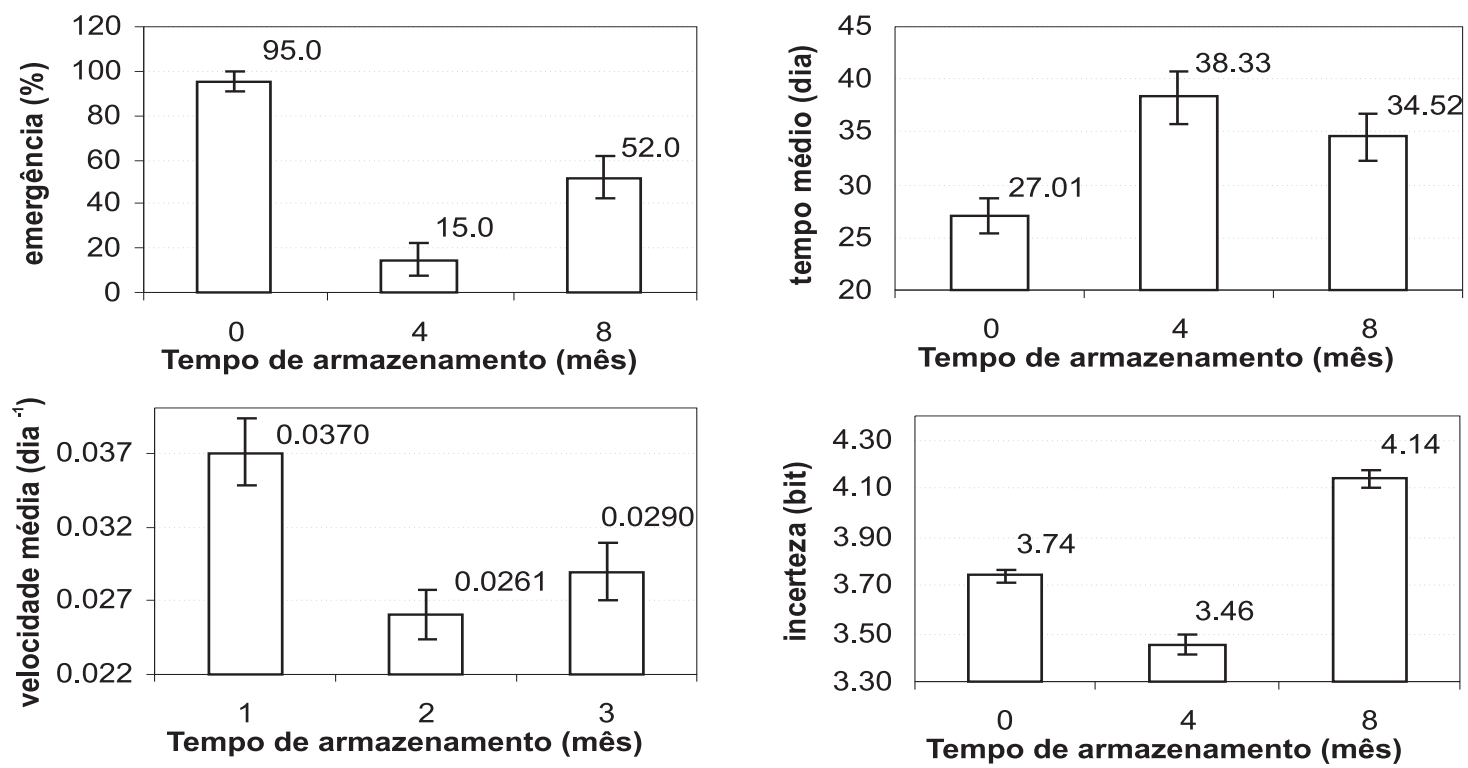

Figura 3 - Emergência de plântulas oriundas de sementes da matriz 2 recém-colhidas (sem arilo e intactas) e de sementes armazenadas por quatro e oito meses (sem arilo e intactas) de Copaifera langsdorffii Desf., Vale do Rio Araguari, MG, safra 2005, mantidas em estufa semiaberta. As barras representam o intervalo de confiança a 0,05 de significância.

Figure 3 -Seedling emergence from newly-collected seeds of the matrix 2, (without aril and without scarification) and stored during four and eight months (without aril and without scarification) of Copaifera langsdorffii Desf.; Araguari River Valley, MG, 2005 crop, cultivated in green house. The bars represent the confidence interval at 0.05 of significance.

O armazenamento das sementes da matriz 2 tornou o processo de emergência mais lento do que o registrado nas sementes recém-colhidas e mais assíncrono, ao final de oito meses de armazenamento. Com quatro meses de idade, as poucas sementes viáveis apresentaram qualidade fisiológica similar, e as plântulas emergiram com maior sincronia (Figura 3 ).

Embora não existam mensurações para sementes de Copaifera langsdorffii, a quantidade de derivados de ácidos graxos das sementes dessa espécie deve ser relativamente alta, como é o caso das sementes de C. officinalis L. (VEIGA JÚNIOR et al., 2007). Essa característica também está associada à deterioração, como o que é registrado em sementes de espécies comerciais, como as do algodoeiro (CUNHA, 2002).

Os dados deste trabalho acrescentam informações novas sobre a fisiologia das sementes da espécie até então relacionada com dormência física sensu Nikolaeva (BASKIN e BASKIN, 1998), decorrente da impermeabilidade do tegumento; dormência química em razão da presença de inibidores de germinação; e dormência fisiológica devido aos inibidores de germinação contidos no embrião. Esses dados são relevantes na exploração econômica para a produção de mudas e para a conservação dessa espécie em bancos de germoplasma. Outro aspecto importante que deve ser destacado é que a supra-anualidade na produção de sementes, com a entressafra de baixa produção, caracteriza o que se pode chamar de evento raro. Os resultados aqui apresentados indicam que, mesmo com escassez de sementes, estas são de boa qualidade e viabilizam a produção de mudas na entressafra.

\section{AGRADECIMENTOS}

À Fundação de Amparo à Pesquisa de Minas Gerais (FAPEMIG, Processo EDT 1370/06), pelo apoio financeiro e pela concessão da Bolsa de Apoio Técnico à primeira autora; à equipe de coleta de sementes e à equipe do Laboratório de Ecofisiologia Vegetal/UFU, pela eficiente contribuição.

\section{REFERÊNCIAS}

ALMEIDA, S. P. et al. Cerrado: espécies vegetais úteis. Planaltina: Embrapa-CPAC, 1998. 464p. 
BARROSO, G. M. et al. Frutos e sementes: morfologia aplicada à sistemática de dicotiledôneas. Viçosa, MG: Universidade Federal de Viçosa, 1999. 443p.

BASKIN, C. C.; BASKIN, J. M. Seeds: ecology, biogeography, and evolution of dormancy and germination. New York: Academic Press, 1998. 66p.

BORGES, E. E. L.; BORGES, C. G. Germinação de sementes de Copaifera langsdorffii Desf. provenientes de frutos com diferentes graus de maturação. Revista Brasileira de Sementes, v.1, n.3, p.45-47, 1979.

BROWN, R. F.; MAYER, D. G. Representing cumulative germination. 1. A critical analysis of single-value germination indices. Annals of Botany, v.61, n.2, p.117-125, 1988.

CARVALHO, D. et al. Eletroforese de proteínas e izoenzimas em sementes de Copaifera langsdorffii (Leguminosae Caesalpinoideae) envelhecidas artificialmente. Revista Árvore, v.30, n.1, p.19-24, 2006.

CARVALHO, M. P.; SANTANA, D. G.; RANAL, M. A. Emergência de plântulas de Anacardium humile A. St.-Hil. (Anacardiacae) avaliada por meio de amostras pequenas. Revista Brasileira de Botânica, v.28, n.3, p.627-633, 2005.

CARVALHO, P. E. R. Espécies arbóreas brasileiras. Brasília: Embrapa Informação Tecnológica, 2003. v.1. 1039p.

CRESTANA, C. M.; BELTRATI, C. M. Morfologia e anatomia das sementes de Copaifera langsdorffii Desf. (Leguminosae-Caesalpinoideae).

Naturalia, v.13, n.1, p.45-54, 1988.

CUNHA, C. M. G. Qualidade fisiológica de sementes de algodoeiro (Gossypium hirsutum L. cv. DeltaOPAL) em função de tamanho e local de produção. 2002. $55 \mathrm{f}$. Dissertação (Mestrado Agronomia) - Universidade Federal de Uberlândia, Uberlândia, 2002.

DIAS, H. C. T. Fenologia de quatro espécies arbóreas e variação temporal e espacial da produção de serapilheira em área de floresta estacional semidecídua em Lavras, MG. Revista Cerne, v.11, Suplemento, p.6-8, 2005.
DORNELES, M. C.; RANAL, M. A.; SANTANA, D. G. Germinação de diásporos recém-colhidos de Myracrodruon urundeuva Allemão

(Anacardiacae) ocorrente no cerrado do Brasil Central. Revista Brasileira de Botânica, v.28, n.2, p.399-408, 2005.

EIRA, M. T. S.; MARTINS NETTO, D. A.

Germinação e conservação de sementes de espécies lenhosas. In: RIBEIRO, J. F. (Ed.). Cerrado: matas de galeria. Planaltina: EmbrapaCPAC, 1998. p.97-117.

EIRA, M. T. S. et al. Conservação de sementes de Copaifera langsdorffii Desf. Leguminosae.

Revista do Instituto Florestal, v.4, p.523-526, 1992.

FREITAS, C. V.; OLIVEIRA, P.E. Biologia reprodutiva de Copaifera langsdorffii Desf. (Leguminosae, Caesalpinioideae). Revista Brasileira de Botânica, v. 25, n.3, p.311-321, 2002.

GOODCHILD, N. A.; WALKER, M. G. A method of measuring seed germination in physiological studies. Annals of Botany, n.35, p.615-621, 1971.

IB AMA. Flora: Lista oficial de flora ameaçada de extinção. 1992. Disponível em: <http://www.ibama.gov.br/flora/extincao.htm>. Acesso em: 09 dez. 2005.

KÖPPEN, W. Climatología: con un estudio de los climas de la Tierra. México: Fondo de Cultura Economica, 1948. 478p.

LEAL, J. R.; OLIVEIRA, P. S. Interactions between fungus-growing ants (Attini) fruits and seeds in cerrado vegetation in Southeast Brazil.

Biotropica, v.30, n.2, p.170-178, 1998.

LORENZI, H. Árvores brasileiras: manual de identificação e cultivo de plantas arbóreas nativas do Brasil. Nova Odessa: Plantarum, 1992. 168p.

MARCOS FILHO, J. Fisiologia de sementes de plantas cultivadas. Piracicaba: Fealq, 2005. 495p.

R. Árvore, Viçosa-MG, v.33, n.4, p.643-652, 2009 
MARTINS, K. et al. Estrutura genética populacional de Copaifera langsdorffii Desf. (LeguminosaeCaesalpinoideae) em fragmentos flroestais no Pontal do Paranapanema, SP, Brasil. Revista Brasileira de Botância, v.31, n.1, p.61-69, 2008.

MELO, J. T. et al. Coleta, propagação e desenvolvimento inicial de espécies do Cerrado. In: SANO, S. M.; ALMEIDA, S. P. (Eds.).

Cerrado: ambiente e flora. Planaltina: EmbrapaCPAC, 1998. p.195-243.

NEWSTROM, L. E.; FRANKIE, G. W.; BAKER, H. G. A new classification for plant phenology based on flowering patterns in lowland tropical forest trees at La Selva, Costa Rica. Biotropica, v.26, n.2, p.141-159, 1994.

PEDRONI, F.; SANCHEZ, M.; SANTOS, F. A. Fenologia da copaíba (Copaifera langsdorffii Desf. Leguminosae, Caesalpinioideae) em uma floresta semidecídua no sudeste do Brasil.

Revista Brasileira de Botânica, v.25, n.2, p.183-194, 2002.

PIZO, M. A.; PASSOS, L.; OLIVEIRA, P. S. Ants as seeds dispersers of flesh diaspores in Brazilian Atlantic Forests. In: FORGET, M. et al. (Eds.). Seed fate: predation, dispersal and seedling establishment. Panama City: CAB International, 2005. p.315-329.

POLO, M.; PAES, J. P. A. Compostos cumarínicos em sementes imaturas de copaíba vermelha (Copaifera langsdorffii Desf.). Revista da Universidade de Alfenas, v.1, n.5, p.26-29, 1994.

RANAL, M. A. Soil spore bank of ferns in a gallery forest of the Ecological Station of Panga, Uberlândia, MG, Brazil. American Fern Journal, v.93, n.3, p.97-115, 2003.

RANAL, M. A.; SANTANA, D. G. How and why to measure the germination process? Revista Brasileira de Botânica, v.29, n.1, p.1-11, 2006.
RIGAMONTE-AZEVEDO, O. C.; WADT, P. G. S.; WADT, L. H. O. Potencial de produção de óleoresina de copaíba (Copaifera spp.) de populações naturais do sudoeste da Amazônia. Revista Árvore, v.30, n.4, p.583-591, 2006.

RODRIGUES, M. et al. O tucanuçu (Ramphastos toco) como agente dispersor de sementes de copaíba. Melopsittacus, v.3, n.1, p.6-11, 2000.

SALOMÃO, A. N. et al. Germinação de sementes e produção de mudas de plantas do Cerrado. Brasília: Rede de Sementes do Cerrado, 2003. 96p.

SANTANA, D. G.; RANAL, M .A. Análise da germinação: um enfoque estatístico. Brasília: Universidade de Brasília, 2004. v.1. 247p.

SANTANA, D. G. et al. Germination measurements to evaluate in allelopathic interactions. Allelopathic Journal, v.17, n.1, p.43-52, 2006.

SCHIAVINI, I.; RESENDE, J. C. F.; AQUINO, F. G. Dinâmica de populações de espécies árboreas em mata de galeria e mata mesófila na margem do ribeirão Panga, MG. In: RIBEIRO, J. F.; FONSECA, C. E. L.; SOUSA-SILVA, J. C. Cerrado: caracterização e recuperação de matas de galeria. Planaltina: Embrapa Cerrados, 2001. p.267-302.

VEIGA JÚNIOR, V. F.; PINTO, A. C. O gênero Copaifera L. Química Nova, v.25, n.2, p.273-286, 2002.

VEIGA JÚNIOR, V. F. et al. Constituintes das sementes de Copaifera officinalis L. Acta Amazonica, v.37, n.1, p.123-126, 2007.

VILELA, N. A. Efeito do arilo na germinação de sementes de Copaifera langsdorffii Desf. 1993. 14f. Monografia (Curso de Ciências Biológicas) - Instituto de Ciências Biológicas, Universidade de Alfenas, Alfenas, 1993. 